\title{
Lista de discussão como estratégia de ensino-aprendizagem na pós-graduação em Saúde
}

Lidia Ruiz-Moreno ${ }^{1}$

Silvia Elsa Lizarralde Pittamiglio ${ }^{2}$

Meiry Akiko Furusato ${ }^{3}$

\author{
Sou um ser apaixonado pelo futuro, \\ e proponho a vocês um exercício de reflexão \\ sobre o que poderia ser \\ a civilização da inteligência coletiva. \\ Pierre Levy (2000, p.4)
}

O uso de novas tecnologias de mediação eletrônica entusiasma grande número de alunos, professores e gestores. Porém, seu desenvolvimento cria desafios aos atores do processo educativo. Souza (2003) questiona os seguintes aspectos sobre sua utilização: qual a pertinência e qualidade da aprendizagem nesses contextos? Como aperfeiçoar os espaços e as tecnologias para que a aprendizagem aconteça? Qual a concepção do processo ensino-aprendizagem utilizada? O uso desses recursos promove um processo efetivo de inclusão social?

A utilização de novos meios eletrônicos de interação, incentivada pela necessidade de se aprimorar o processo de ensino-aprendizagem num mundo cada vez mais complexo, no qual as informações se disseminam velozmente, demanda uma ressignificação do papel de alunos e professores nos diferentes cenários educativos.

No modelo pedagógico vigente na maioria das escolas, o aluno é visto como um receptor de conteúdos cuja tarefa é assimilar e reproduzir, ao invés de problematizar, analisar, refletir, discutir e conversar. Em processos de ensino controladores, com professores autoritários, pouco se avança na formação de profissionais capazes de atender às necessidades sociais atuais (Perrenoud, 2000).

Souza (2006) nos alerta sobre a escassez de experiências bem-sucedidas de introdução de tecnologias da informação na rede pública de Ensino Fundamental e Médio na América Latina, e do grande atraso na implantação e apropriação destas ferramentas no Ensino Superior. Segundo o autor, existem também experiências de sucesso, mas freqüentemente se observa a incorporação de tecnologia informática em disciplinas de cunho conteudista, empregando métodos tradicionais de ensino e avaliação.

Moreira, Costa e Oliveira (2001) situam três principais concepções do processo de ensino-aprendizagem que determinam a prática pedagógica com uso da tecnologia educacional. Na concepção empirista, o aluno é considerado um ser

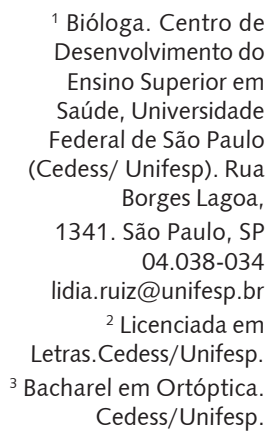
Borges Lagoa, 04.038-034 lidia.ruiz@unifesp.br 2 Licenciada em Letras.Cedess/Unifesp. ${ }^{3}$ Bacharel em Ortóptica. Cedess/Unifesp. 
passivo onde são depositados os conhecimentos, configurando o que Freire $(1975$, p.70) chama de "educação bancária". Neste modelo, o uso de tecnologias consiste em disponibilizar conteúdos no ambiente tecnológico por meio de recursos, como textos, sons, animações, softwares e vídeos e, ao finalizar o processo, realizar avaliações para testar os conteúdos adquiridos. Já, na concepção racionalista, a aprendizagem é um processo autônomo regulado pelo amadurecimento orgânico das estruturas racionais. As atividades são centradas no aluno, que depende exclusivamente do seu potencial cognitivo para realizar a aprendizagem, sendo secundarizada a mediação docente neste processo.

As dicotomias das concepções empirista e racionalista são superadas no modelo construtivista, baseado na teoria sociointeracionista de Vigotsky (1995), que enfatiza a construção de conhecimentos mediante as trocas que o indivíduo realiza com seu ambiente. Na visão de Moreira, Costa e Oliveira (2001), é a abordagem construtivista a que contextualiza de forma mais adequada o aproveitamento dos recursos tecnológicos para o processo de ensino-aprendizagem.

Uma das possibilidades de se estabelecerem transformações no sistema educacional consiste em desenvolver processos de comunicação, que envolvam as dimensões cognitivas, afetivas, sociais e éticas, entre alunos e professores abertos, democráticos e interativos (Moran, 2003). Valorizam-se, cada vez mais, a interação e a troca de informações entre os atores envolvidos no processo educativo e o estímulo à criatividade em substituição à reprodução passiva de conhecimentos já existentes.

$\mathrm{Na}$ abordagem pedagógica interacionista, a aprendizagem é um processo social e o ato de ensinar consiste em estabelecer uma série de inter-relações que facilitem a elaboração de representações pessoais sobre o objeto da aprendizagem.

Consideramos que uma educação que propicie a autonomia, liberdade, cooperação e solidariedade pode acontecer com ou sem o uso de novas tecnologias de mediação eletrônica. O que promove o processo educativo é a atitude e o compromisso dos sujeitos em estabelecer processos comunicativos autênticos, considerando os diferentes contextos institucionais, sociais e políticos (Freire, 2003). Mas, educar também é estar atento às diferentes possibilidades e recursos que nossa realidade nos apresenta; a diversificação de instrumentos, estratégias e ambientes de ensino-aprendizagem pode aumentar as possibilidades de interação, criar condições para a autonomia, respeitando os diferentes ritmos, momentos e estilos cognitivos.

O uso de tecnologias que facilitam o acesso e troca de informações, ampliando a possibilidade de escolha de alunos e docentes, pode constituir um facilitador do processo educativo. Em relação ao acesso da população à informação, Vigotsky (1995) define a tecnologia como um dos mediadores culturais, criados pelo homem, que possibilitam sua relação com o mundo material.

Os ambientes de comunicação mediados por computadores com acesso à internet propiciam o desenvolvimento de interações educativas mais amplas, impensáveis no passado recente, sendo possível combinar momentos presenciais e a distância, onde os participantes podem trocar idéias e experiências, vivenciar atividades individuais e grupais, e criar condições para a construção de conhecimentos de forma colaborativa (Kenski, 2001).

O aprendizado acontece quando se estabelecem determinadas dinâmicas de troca e relacionamentos, intelectuais e afetivos, com vistas a alcançar objetivos específicos, constituindo-se, assim, as comunidades virtuais (Soares, 2003). Souza (2003) define estes agrupamentos como " [...] comunidades de pessoas compartilhando interesses comuns, idéias e relacionamentos, por meio da Internet ou outras redes colaborativas" (p.98). O autor observa também que as interações on-line promovem um maior grau de profundidade, permitem a discussão simultânea de diversos tópicos e ampliam as possibilidades espaço-temporais.

Sem dúvida, a utilização desses recursos cria desafios tanto para docentes quanto para alunos, os quais devem saber: lidar com os equipamentos, navegar na internet, desenvolver a capacidade de leitura de hipertextos multimodais, operar softwares e assimilar conceitos e vocabulário próprios de uma nova área. As instituições também são mobilizadas a disponibilizar uma infra-estrutura física adequada, promover cursos de educação continuada em novas tecnologias e incentivar o uso dos ambientes virtuais (Pittamiglio, 2004).

O docente, como mediador do processo, deve desenvolver flexibilidade e intuição para lidar com a incerteza, a provisoriedade e o volume crescente de informações na sua área de atuação. Segundo 
Blikstein e Zuffo (2003), é urgente a formação de educadores que lidem com as novas tecnologias de forma crítica e reflexiva para superar resistências e preconceitos, ou, ainda, evitar a ilusão de que esses novos instrumentos per se poderiam ser a solução para todos os problemas educacionais da atualidade.

Os alunos, por sua vez, precisam desenvolver competências, como a busca ativa de informação e senso crítico, além de uma participação responsável no processo de aprendizagem e avaliação. Geralmente, eles apresentam maior familiaridade com essas ferramentas, mas é preciso que também desenvolvam habilidades como: intuição, bom senso, sentido estético, capacidade para selecionar e comparar diante de tantas possibilidades que lhe são oferecidas.

Azevedo $(2005$, p.2) acredita que alunos e docentes precisam de uma espécie de "pré-escola virtual" que os aproxime do "letramento digital", o que envolve não só o desenvolvimento de habilidades procedimentais, mas também uma mudança conceitual sobre as representações do tempo e do espaço no chamado "mundo virtual" ou "ciberespaço".

Dentre os diversos ambientes virtuais, possíveis de serem utilizados como estratégias de ensinoaprendizagem, a lista de discussão por meios informatizados representa uma oportunidade para que um grupo de pessoas "possa debater e aprofundar a distância um tema sobre o qual sejam especialistas ou tenham realizado estudo prévio" (Anastasiou, Alves, 2004, p.85).

Foi refletindo sobre estas questões que incluímos, a partir de 2004, a lista de discussão como uma estratégia de ensino-aprendizagem, junto com dramatizações, mapa conceitual, técnicas de sensibilização, júri simulado, no módulo de Práticas Educativas, no curso de especialização em Ensino em Ciências da Saúde, do Centro de Desenvolvimento do Ensino Superior em Saúde (Cedess), da Universidade Federal de São Paulo (Unifesp). Desta forma, o módulo passou a se estruturar numa modalidade semipresencial, alternando momentos presenciais e a distância. A escolha da lista de discussão, como estratégia de comunicação a distância, foi motivada por: permitir a participação de forma assíncrona, não requerer a instalação de softwares especiais, ser disponibilizada gratuitamente em diversos provedores comerciais de internet e apresentar uma interface amigável, praticamente intuitiva, que incentiva o seu uso. Ademais, essa ferramenta de fácil acesso permite o registro das interações, a geração de estatísticas e representa o principal suporte de diversas comunidades virtuais.

Num momento em que as instituições de ensino superior ampliam propostas educativas de caráter semipresencial, com utilização de tecnologias de mediação eletrônica, amparadas em portaria do Ministério de Educação (Brasil, 2004) que permite que os cursos de ensino superior ofereçam até 20\% da carga horária a distância, consideramos relevante compartilhar experiências que utilizem ambientes virtuais, como forma complementar aos encontros presenciais. É importante empreender investigações no contexto particular dos meios eletrônicos de interação como suporte à educação, com a finalidade de afinar uma metodologia coerente com o modelo pedagógico orientado ao desenvolvimento do pensamento crítico dos estudantes, e que valorize o papel motivador, condutor e mediador do docente numa comunidade virtual de aprendizagem (Fëderov, 2006).

Avanços no conhecimento sobre o papel das tecnologias de mediação eletrônica no processo educativo devem incluir a perspectiva dos sujeitos participantes. Assim, o objetivo central do presente trabalho foi analisar a lista de discussão como estratégia de ensino-aprendizagem numa proposta educativa semipresencial, sendo que, especificamente, nos propusemos a identificar facilidades, dificuldades e expectativas dos participantes sobre a utilização dessa estratégia em espaços formais de ensino-aprendizagem. Para a consecução destes objetivos, analisamos dados quantitativos, aplicamos questionários e realizamos o registro dos debates sobre o papel da lista de discussão no processo de ensino-aprendizagem.

\section{A experiência vivenciada}

No módulo de Práticas Educativas foi criada uma lista de discussão da qual participaram 24 alunos e três professores. A maioria dos alunos (quatro homens e vinte mulheres) - formados em Enfermagem (oito), Psicologia (um), Biomedicina (dois), Fisioterapia (quatro), Nutrição (quatro), Odontologia (dois), Ortóptica (um), Farmácia (dois), Serviço Social (um), Administração (um), Medicina (um) e Educação Física (um) - não tinha participado previamente de listas de discussão. 
No primeiro encontro presencial do módulo, foi realizada uma avaliação diagnóstica, por meio do mapeamento das experiências anteriores dos participantes na utilização dos meios eletrônicos e ambiente virtual. Além disso, foram apresentadas orientações sobre o uso da lista de discussão e acerca dos papéis de liderança a serem desenvolvidos pelos participantes (administrador técnico, moderador/ animador e tutor/professor). Uma vez distribuídos os papéis e definida a forma de participação, um aluno, no papel de administrador técnico, criou a lista de discussão, num provedor comercial gratuito de internet, cadastrou os participantes e configurou a página de forma que fosse restrita ao grupo. Foi combinado que o papel de líder seria temporário, dando oportunidade a vários alunos para vivenciá-lo de forma alternada.

As atividades a distância, no primeiro intervalo de 15 dias, comportaram a veiculação de questões operacionais e de "etiqueta" referentes à utilização da lista. O aluno moderador/animador disponibilizou os tópicos a serem debatidos, que incluíam diferentes estratégias de ensinoaprendizagem, como aula expositiva dialogada, mapa conceitual, júri simulado. Os alunos foram orientados a relatar experiências, conhecimentos prévios, discutir sobre as vantagens e desvantagens da utilização das diferentes estratégias didáticas, e a consultar fontes bibliográficas. Para subsidiar a discussão, foram disponibilizados arquivos de texto e links para artigos, capítulos de livros e sites pertinentes.

Além da comunicação muitos-para-muitos, possibilitada pela lista de discussão, foram utilizados outros recursos presentes na página do grupo, tais como: ativação de links, carregamento de arquivos, uso da agenda e aplicação de enquetes.

No segundo encontro presencial, foram vivenciadas algumas das estratégias didáticas discutidas previamente na lista de discussão e apresentadas as expectativas e dificuldades iniciais de utilização do espaço virtual. O planejamento coletivo das próximas atividades a distância, que seriam realizadas nos 15 dias seguintes, previu o uso de enquetes, além da participação nas discussões em andamento.

Foi promovido, no terceiro encontro presencial, um debate com análise reflexiva para avaliação da experiência semipresencial vivenciada, e solicitada, aos alunos, a entrega de um relatório com as sínteses das produções individuais e coletivas. As expectativas, possibilidades, dificuldades e o papel da lista de discussão no processo de ensino-aprendizagem foram os núcleos orientadores da elaboração do relatório.

\section{Resultados e discussão}

Os dados mostraram que vinte alunos (83\%) dos 24 alunos participantes trocaram 175 mensagens, durante o módulo Práticas Educativas, e a média de mensagens foi de seis por dia. Dois alunos (6\%) emitiram 54 mensagens (31\%), "é fato constatado que um número pequeno de membros é responsável por grande parte das mensagens" (Souza, 2003, p.102). Neste caso, esses dois participantes ocuparam a função de animadores da lista, o que pode justificar a sua maior participação.

Foram disponibilizados 13 arquivos (um cronograma das atividades previstas, 11 textos sobre estratégias de ensino-aprendizagem e novas tecnologias, e um projeto de pesquisa), três enquetes sobre auto-avaliação, cinco fotos, e foram agendados dois seminários acadêmicos.

Foram identificadas mensagens de cunho técnico, social e de conteúdo específico do módulo, conforme classificação de Mckenzie e Murphy (2000). As mensagens foram tabuladas, classificadas e quantificadas por: emissor, freqüência de participação e assuntos discutidos, os quais abrangeram, além daqueles focalizando as diferentes práticas educativas, experiências prévias sobre o objeto de estudo da disciplina. Também foram abordados temas como: a maturidade do aluno frente às novas práticas educativas a distância; sua resistência a mudanças, enraizada nas experiências formativas em modelos tradicionais de ensino; aspectos do contexto político-institucional; a importância da relação professor/ aluno; a necessidade de respeito aos limites de ambos; a valorização do conhecimento prévio, e a subjetividade implícita na construção do conhecimento.

As expectativas mais citadas foram: estabelecer um canal de comunicação a distância assíncrono para favorecer as relações interpessoais, contar com apoio emocional, trocar informações atualizadas com 
colegas e professores, documentar o processo, e ampliar os momentos de comunicação fora da sala de aula - "Somos unidos, mas precisamos criar, ter e manter um canal ao qual poderemos manifestar nossas alegrias, construções deste aprendizado... nossas angústias... Isso nos aproxima, ou seja, poder acrescentar este espaço virtual para dentro de nossas casas e ambiente de trabalho" (Aluno 3).

Entre as principais motivações, os alunos citaram: interesse em participar de uma comunidade de aprendizagem, percepção dos problemas comuns aos membros, e o compromisso com a formação ética e cidadã:
Vejo que estamos com a mesma expectativa, ansiedade e frustração, pois queremos ser educadores diferentes, com metodologias diferentes, centrados no aluno, no processo ensino-aprendizagem adequado. Infelizmente encontramos barreiras como as já citadas: classes numerosas, alunos desmotivados e instituições (direção, coordenação) que não estão preocupadas com isto. Não podemos desanimar, e sim buscar forças para formarmos cidadãos éticos, competentes e críticos. (Aluno 10)

As principais dificuldades referiram-se à: disponibilidade de recursos de acesso à internet, inexperiência em atividades de ensino a distância, administração do tempo para ler e responder a grande quantidade de mensagens geradas, e ausência de contato pessoal.

Azevedo (2008) relata que a falta de tempo foi o principal motivo de evasão alegado por alunos em diferentes experiências de educação a distância por ele desenvolvidas. Na opinião do autor, os alunos acostumados à exigência sincrônica dos ambientes presenciais devem aprender a administrar o tempo na perspectiva da temporalidade multissíncrona dos ambientes virtuais, que admitem diferentes possibilidades e ritmos de participação.

Entre os desafios para a utilização da lista de discussão como ferramenta educativa, foram citados: (i) maturidade dos alunos, conhecimento dos fundamentos e objetivos da prática educativa, definição do papel de cada ator e necessidade de mediação docente.

Quanto às vantagens, os especializandos destacaram: as facilidades de comunicação espaçotemporais, a superação da timidez evidenciada por alguns participantes na comunicação em sala de aula, a aproximação de pessoas que não demonstraram afinidades nos encontros presenciais, e a atitude solidária dos colegas: "Às vezes tínhamos algum problema e quando pedíamos ajuda a alguém em particular, sempre o grupo todo se manifestava. Isto é muito bom e ajudou no nosso entrosamento e maior conhecimento dos colegas propiciado pela lista de discussão" (Aluno 17).

O grupo valorizou a afetividade presente no processo de ensino-aprendizagem, dimensão que Soares (2003) destaca como fundamental nos inter-relacionamentos a distância. O respeito pela opinião alheia, sem julgamento pessoal, onde todos puderam se expressar livremente entendendo que não existe verdade absoluta sobre determinado assunto, senão a interação de idéias, foram aspectos valorizados pelo grupo. Assim, a colaboração no ambiente virtual foi vivenciada como essencial para a aprendizagem, de modo que professores e alunos puderam trabalhar juntos na construção e socialização do conhecimento.

Os pós-graduandos participantes da experiência expressaram sua satisfação na utilização desta ferramenta, mas ainda se mostraram inseguros para aplicá-la em outros cenários formativos: "Acho que ainda não sei elaborar uma lista de discussão com meus alunos, mas vou procurar saber como fazer, ainda não tentei" (Aluno 7).

A expansão de cursos que utilizem educação a distância requer, dentre outros fatores, a implementação de processos de formação docente que desenvolvam um preparo técnico-pedagógico para se perceberem as possibilidades geradas pelos recursos presentes na educação on-line e nos ambientes virtuais de aprendizagem como um espaço de efetiva organização do trabalho pedagógico, mas também como um suporte para transcender o modelo tradicional unidirecional de ensino.

Os professores podem ser atores importantes para orientar processos de inclusão digital. A apropriação da cultura digital de um número crescente de professores, que lhes permita ampliar seu próprio horizonte de formação e informação, é de fundamental importância para programar novas propostas educativas no âmbito do ensino, da pesquisa e da extensão (Giordan, Starobinas, Schwartz, 2005). 


\section{Comentários finais}

As instituições educativas, preocupadas com a formação de cidadãos críticos, reflexivos e responsáveis pelo seu aprendizado, têm de se adequar aos novos ambientes, criando mecanismos didático-pedagógicos que favoreçam o uso de novas tecnologias de forma dinâmica e contínua. Pesquisas na área do ensino de ciências sinalizam que a informática aplicada à educação vem transformando as estratégias convencionais de ensino. As interações ocorridas no espaço social da sala de aula são ampliadas com a utilização de meios de comunicação como a internet. Numa experiência de desenvolvimento de projetos de defesa ambiental, relatada por Moreira Machado (2002), trabalhouse numa visão interacionista, buscando colocar professor e alunos sempre de forma ativa, construindo os seus conhecimentos em ambientes interativos virtuais.

$\mathrm{Na}$ experiência vivenciada no módulo de Práticas Educativas, no curso de especialização em Ensino em Ciências da Saúde, o grupo mostrou grande motivação em participar da lista de discussão por meios informatizados num ambiente formal de ensino-aprendizagem na modalidade semipresencial. Acreditamos que um dos fatores que contribuiu foi a mobilização prévia, que compreendeu o planejamento coletivo e a escolha conjunta dos objetos de estudo, tarefas e cronograma de atividades, de forma que professores e alunos se co-responsabilizaram pelo processo. O clima de confiança e comunicação cordial, criado desde o início da proposta, também foi um fator determinante para a expressão de idéias e sentimentos que contribuiu na configuração de uma comunidade de aprendizagem caracterizada pela interação e colaboração. Um aspecto destacado pelos participantes foi o de que as pessoas mais retraídas para a intervenção presencial podem encontrar um espaço mais propício para expressar suas idéias e sentimentos no ambiente virtual. Além disso, a comunicação assíncrona proporciona maior tempo para se pensar sobre o assunto ou procurar informações sobre os temas em pauta, o que constituiu também um fator facilitador das contribuições.

Houve articulação dos conteúdos específicos do módulo com as experiências prévias, possibilitando uma ressignificação das temáticas abordadas. Solicitações de ajuda provocaram trocas de informação para melhor compreensão de alguns conteúdos, configurando um processo de aprendizagem colaborativa, onde os estudantes puderam expor idéias, suposições e conhecimentos a um escrutínio crítico por parte do grupo (Cañas et al., 1997).

Para Vygotsky (1998), a interação social exerce um papel fundamental no desenvolvimento cognitivo, sendo que a origem dos processos de aprendizagem está na relação com outras pessoas, com o uso da linguagem. Para ele, o homem é um ser eminentemente social, e o conhecimento, um produto social. A educaçãa com o emprego de novas tecnologias de informação e comunicação (NTICs) pode oferecer as condições para uma aprendizagem eficaz, alicerçada nos fundamentos sociointeracionistas, sempre que a proposta educativa seja estruturada com processos interativos que favoreçam a construção de um ambiente de colaboração no qual o professor possa orientar e acompanhar o aprendizado do aluno. Para esse autor, cabe ao educador associar aquilo que o aprendiz sabe a uma linguagem culta ou científica, para ampliar os conhecimentos daquele que aprende, de forma a integrá-lo histórica e socialmente no mundo.

No presente trabalho, a lista de discussão evidenciou ser uma estratégia facilitadora das interrelações e do processo de ensino-aprendizagem, já que permitiu o aprofundamento do objeto de estudo, a construção e elaboração de novos elementos conceituais e de sínteses contínuas, onde a emoção e os sentimentos estiveram presentes no estabelecimento da rede de relacionamentos sociais.

A diversificação das estratégias de ensino e a complementação das atividades presenciais e a distância foram valorizadas pelos alunos. Ancoradas na vivência de interação em ambos os ambientes, a alternância na utilização dos espaços fortaleceu as experiências de troca, o que ampliou as possibilidades de compreensão e significação da experiência vivenciada.

Um dos possíveis fatores dificultadores da participação dos alunos no ambiente virtual, além da (in) experiência prévia no uso das ferramentas operacionais, pode estar vinculado às vivências anteriores em situações de ensino transmissivas, que levam a uma postura passiva. Além disso, é importante ressaltar que uma parcela dos alunos participantes não possui acesso domiciliar à internet, aspecto que deve ser considerado pelo professor nas exigências de participação. Segundo o Instituto Brasileiro de Geografia e 
Estatística (IBGE, 2006) o número de domicílios com acesso à internet, no país, é de 16,9\%. Embora em expansão, o porcentual é ainda reduzido e mostra fortes desigualdades regionais. Num movimento de tornar este processo socialmente mais inclusivo, muitas instituições de Ensino Superior (IES) têm disponibilizado laboratórios de informática, que podem ser utilizados em diferentes dias e horários (Anastasiou, Alves, 2004).

Um importante desafio apontado na presente pesquisa é a necessidade de qualificação docente para utilizar recursos tecnológicos de forma a aperfeiçoar o processo de ensino-aprendizagem e, conseqüentemente, a formação profissional nas diferentes áreas. Em particular, a área da saúde constitui um dos setores de maior impacto das NTICs nos campos da educação, assistência à saúde e pesquisa. A troca de informações para diagnósticos, tratamento, prevenção de doenças e processos de educação permanente são alguns dos aspectos que evidenciam a importância de ampliar o uso racional destes recursos (Gutierrez, 2002).

A produção de conhecimento sobre as vantagens, limites e desafios de práticas educativas virtuais amplia cada vez mais as possibilidades de utilização reflexiva destes recursos. De acordo com Marcovitch (1999, p.1):

A informação permeia as ações da universidade. É o objetivo final da pesquisa e o que efetivamente se transmite nas atividades de ensino e de extensão. Descendente direta de estudos exploratórios desenvolvidos há décadas nos laboratórios acadêmicos, a tecnologia da informação volta à universidade como uma espécie de criatura que desafia o criador a decifrá-la incessantemente [...] A universidade, como as pessoas, deve «desaprender» certos métodos, embora mantendo intacto o seu cabedal de conhecimentos. Não se trata de renunciar ao passado, mas de preparar-se para o futuro com sabedoria, lançando mão das armas disponíveis.

\section{Colaboradores}

Os autores Lidia Ruiz-Moreno,Silvia Elsa Lizarralde Pittamiglio e Meiry Akiko Furusato participaram, igualmente, de todas as etapas de elaboração do artigo.

\section{Referências}

ANASTASIOU, L.G.C.; ALVES, L.P. Estratégias de Ensinagem. In: (Orgs.). Processos de ensinagem na universidade: pressupostos para as estratégias de trabalho em aula. 3.ed. Joinville: Ed. Univille, 2004. p.68-100.

AZEVEDO, W. Panorama atual da educação a distância no Brasil. In: Muito além do jardim de infância: temas de educação on-line. Rio de Janeiro: Armazém Digital, 2005. p.13-8.

Muito além do jardim de infância: o desafio do preparo de alunos e professores on- line. Disponível em: <http:www2.abed.org.br/ visualizaDocumento.asp?Documento_ID=65>. Acesso em: 14 nov. 2008.

BLIKSTEIN, P.; ZUFFO, M.K. As sereias do ensino eletrônico. In: SILVA, M. (Org.). Educação on-line: teorias, práticas, legislação e formação corporativa. São Paulo: Loyola, 2003. p.23-38. 
BRASIL. Ministério da Educação e Cultura. Portaria n. 4.059, de 10 de dezembro de 2004. Regulamenta a oferta de disciplinas que utilizem modalidade semipresencial em cursos superiores reconhecidos. Diário Oficial da República Federativa do Brasil, Brasília, DF, 13 dez. 2004. Seção 1, p.34, 2004.

CAÑAS, A.J. et al. Colaboración en la construcción de conocimiento mediante mapas conceptuales. Invited Plenary Talk. In: CONGRESO INTERNACIONAL SOBRE TECNOLOGÍA Y EDUCACIÓN A DISTANCIA, 8., 1997, San José, Costa Rica Proceedings... San José, 1997. p.25-32. Disponível em: <http:// cmap.coginst.uwf.edu>. Acesso em: 7 maio 2008.

FËDOROV, A.N. Siglo XXI, la universidad, el pensamiento crítico y el foro virtual. Rev. Ibero-Am. Educ., v.38, n.5, p.1-10, 2006. Disponível em: <http://www.rieoei.org/ deloslectores/1218Federov.pdf >. Acesso em: 7 maio 2008.

FREIRE, P. Pedagogia da autonomia: saberes necessários à prática educativa. 25.ed. Rio de Janeiro: Paz e Terra, 2003.

Pedagogia do oprimido. 2.ed. Rio de Janeiro: Paz e Terra, 1975.

GIORDAN, M.; STAROBINAS, L.; SCHWARTZ, G. Inclusão digital e reforma

universitária. J. Ciênc., p.3, 2005. Disponível em <http://www.jornaldaciencia.org.br/ Detalhe.jsp?id=26648>. Acesso em: 7 maio 2008.

GUTIERREZ, C.F.F. Las nuevas tecnologias da información y las comunicaciones en salud. Rev. Cubana Educ. Méd. Sup., v.16, n. 2, p.128-39, 2002.

INSTITUTO BRASILEIRO DE GEOGRAFIA E ESTATÍSTICA (IBGE). Pesquisa Nacional por Amostra de Domicílios: acesso à internet e posse de telefone móvel celular para uso pessoal 2005. Rio de Janeiro, 2007. Disponível em: <http://www.ibge.gov.br/home/ estatistica/populacao/acessoainternet/default.shtm>. Acesso em: 7 maio 2008.

KENSKI, V.M. O ensino e os recursos didáticos em uma sociedade cheia de tecnologias. In: VEIGA, I.A. (Org.). Didática: o ensino e suas relações. 6.ed. São Paulo: Papirus, 2001. p.127-47.

LÉVY, P. Cibercultura. Aula inaugural do projeto de implantação de um sistema de ensino a distância na PUC-Minas, p.1-6, 2000. Disponível em <http:// www.inf.pucminas.br/projetos/ead/noticias.php>. Acesso em: 7 maio 2007.

MARCOVITCH, J. Universidade e inovação tecnológica. Rev. Ibero-am. Educação, n.21, p.70-89, 1999. Disponível em: <http://www.rieoei.org/rie21f.htm>. Acesso em: 7 maio 2008.

MCKENZIE, W.; MURPHY, D. "I hope this goes somewhere": evaluation of an on-line discussion group. Austr. J. Educ. Technol..v.16, n.3, p.239-57, 2000. Disponível em: <http://www.ascilite.org.au/ajet/ajet16/mckenzie.html>. Acesso em: 7 maio 2008.

MORAN, J.M. Contribuições para uma pedagogia on-line. In: SILVA, M. (Org.). Educação on-line: teorias, práticas, legislação e formação corporativa. São Paulo: Loyola, 2003. p.39-50.

MOREIRA, M.; COSTA, J.W.; OLIVEIRA, C.C. Ambientes informatizados de aprendizagem. São Paulo: Campinas, 2001.

MOREIRA MACHADO, M.M. A informática no ensino da biologia do meio ambiente. 2002. Dissertação (Mestrado) - Universidade Federal de Santa Catarina, Florianópolis. Disponível em: <http://teses.eps.ufsc.br/defesa/pdf/7792.pdf > . Acesso em: 7 maio 2008.

PERRENOUD, P. 10 novas competências para ensinar. Porto Alegre: Artmed, 2000. 
PITTAMIGLIO, S.E.L. Novas tecnologias e a prática docente: um estudo a partir do livro-texto digital "Aprendendo a estudar". 2004. Dissertação (Mestrado Profissional) - Centro de Desenvolvimento do Ensino Superior em Saúde, Universidade Federal de São Paulo, São Paulo. 2004.

SOARES, I.O. EAD como prática educomunicativa: emoção e racionalidade operativa. In: SILVA, M. (Org.). Educação on-line: teorias, práticas, legislação e formação corporativa. São Paulo: Loyola, 2003. p.95-109.

SOUZA, R.R. Algumas considerações sobre as abordagens construtivistas para utilização de tecnologia na educação. Liinc Rev., v.2, n.1, p.40-52, 2006. Disponível em: <http:// www.ibict.br/liinc/viewarticle.php?id=25\&layout= abstract $>$. Acesso em: 7 maio 2008.

Aprendizagem colaborativa em comunidades virtuais: o caso das listas de discussão. In: COSCARELLI, C.V. (Org.). Novas tecnologias, novos textos, novas formas de pensar. 2.ed. Belo Horizonte: Autêntica, 2003. p.95-110.

VYGOTSKY, L.S. A formação social da mente. 6.ed. São Paulo: Martins Fontes, 1998. . Pensamento e linguagem. São Paulo: Martins Fontes, 1995. 
As novas tecnologias de mediação eletrônica desafiam os atores do processo educativo e requerem a definição do modelo pedagógico adotado. O objetivo deste trabalho foi analisar a lista de discussão como estratégia de ensino-aprendizagem numa proposta educativa semipresencial. A lista de discussão foi criada na disciplina Práticas Educativas do curso de especialização em Educação em Saúde. Os núcleos que orientaram a análise dos dados foram: expectativas, possibilidades, dificuldades e papel da lista de discussão no processo de ensino-aprendizagem, na ótica dos discentes. As dificuldades se centraram na disponibilidade de acesso a internet, inexperiência, administração do tempo e ausência de contato pessoal. Quanto às possibilidades, destacaram-se as facilidades espaço-temporais, a ampliação dos canais de comunicação assíncrona e a criação de uma comunidade colaborativa de aprendizagem.

Palavras-chave: Tecnologia educacional. Lista de discussão. Estratégias de ensino-aprendizagem. Construtivismo. Educação em saúde.

\section{Discussion lists as a teaching and learning strategy for postgraduate health studies}

New electronic mediation technologies challenge the players in the educational process and make it necessary to define the pedagogical model adopted. The aim of this study was to analyze discussion lists as a teaching and learning strategy for a semi-distant educational proposal. A discussion list was created within the discipline of Educational Practices of a health education specialization program. The core issues guiding the data analysis were the expectations, possibilities, difficulties and role of the discussion list within the teaching and learning process from the students' point of view. The difficulties were centered on the availability of internet access, inexperience, time management and lack of personal contact. Space-time facility, expansion of asynchronous communication channels and creation of a collaborative learning community were among the possibilities highlighted.

Key words: Educational technology. Discussion list. Teaching and learning strategies. Constructivism. Health education.

\section{Lista de discusión como estrategia de enseñanza-aprendizaje en el postgrado en salud}

Las nuevas tecnologías de mediación electrónica desafían a los actores del proceso educativo y requieren la definición del modelo pedagógico adoptado. El objetivo de este trabajo es analizar la lista de discusión como estrategia de la enseñanzaaprendizaje en una propuesta educativa semi-presencial. La lista de discusión se creó en la disciplina Prácticas Educativas del curso de especialización en Educación en Salud. Los núcleos que orientan el análisis de los datos son: expectativas, posibilidades, dificultades y papel de la lista de discusión en el proceso de enseñanza-aprendizaje en la óptica de los discentes. Las dificultades se centraron en la disponibilidad de acceso a Internet, inexperiencia, administración del tiempo y ausencia de contacto personal. Respecto a las posibilidades, se destacan las facilidades espacio-temporales, la ampliación de los canales de comunicación asíncrona y la creación de una comunidad colaborativa de aprendizaje.

Palabras clave: Tecnología educacional. Lista de discusión. Estrategias de enseñanza-aprendizaje. Constructivismo. Educación en salud. 